See discussions, stats, and author profiles for this publication at: https://www.researchgate.net/publication/228626810

\title{
A status theory of collective action
}

Article in Advances in Group Processes · September 2009

DOI: 10.1108/S0882-6145(2009)0000026009

CITATIONS

34

15 authors, including:

ese Michael Hout

(1) New York University

109 PUBLICATIONS 6,769 CITATIONS

SEE PROFILE

Some of the authors of this publication are also working on these related projects:

Religious change in the USA View project
READS

2,121

Edward J. Lawler

Cornell University

126 PUBLICATIONS 10,970 CITATIONS

SEE PROFILE 


\title{
A Status Theory of Collective Action
}

\author{
Robb Willer \\ University of California, Berkeley
}

*Contact Robb Willer at Department of Sociology, University of California, Berkeley, CA 94720. Willer@ Berkeley.edu, Phone: (607) 339-6466, Fax: (510) 642-0659. I thank Pat Barclay, Stephen Benard, Shelley Correll, Claude S. Fischer, David Grusky, Michael Hout, James Kitts, Edward J. Lawler, Michael Lovaglia, Michael Macy, Brent Simpson, Ann Swidler and David Willer for contributions to earlier versions of this paper, and the National Science Foundation for supporting this research, grant number SES0405352. 


\begin{abstract}
Here I present a theory of collective action that emphasizes the role of status. I argue that collective action contributions earn individuals improved status by signaling their concern for the group's welfare relative to their own. Having received greater prestige for their contributions to group goals, individuals' actual motivation to help the group is increased, leading to greater subsequent contributions to group efforts and greater feelings of group solidarity. This "virtuous cycle" of costly contributions to group efforts and enhanced standing in the group shows one way in which individuals' prosocial behaviors are socially constructed, a consequence of individuals' basic concern for what others think of them. I discuss a variety of issues related to the theory, including its scope of application, theoretical implications, relationship to alternative models of reputation and prosocial behavior, possible practical applications, and directions for future research.
\end{abstract}




\section{A STATUS THEORY OF COLLECTIVE ACTION}

\section{INTRODUCTION}

Much of collective action theory and research is concerned with identifying and evaluating solutions to the "collective action problem" or "free-rider problem." The collective action problem emerges in group settings where all individuals can materially profit by not contributing to the group (Olson 1965). ${ }^{1}$ However, when all individuals withhold contribution, collective action fails and all are worse off. If individuals all act in their own material self-interest in these situations it would seem impossible for public goods to be produced.

In this way collective action entails a conflict between individual and group level rationality. Though all are individually tempted not to contribute, low levels of contribution leave the entire community worse than if all had contributed. Because of this tension between individual and collective interests, collective action represents a social dilemma, where what is rational, in the narrow economic sense, at the individual level is irrational for the group.

In collective action settings individuals are deterred from contributing by one or both of two factors: the temptation to free-ride and the fear of inefficacy. The temptation to free-ride reflects a desire to let others carry the burden of contributing to collective action. The fear of inefficacy reflects individuals' concerns that their contributions will not have a meaningful impact on the production of the public good. The classic collective action problem that is the focus of the present research, such as that faced when organizing a demonstration, strike, or social movement, involves both motives for defection.

As an example, organizing a demonstration entails a significant collective action problem. Let's say that you are considering attending an anti-war demonstration. You agree with the cause and would like to attend, but at the same time it will be costly to you as there are other things you might wish to do with your time (temptation to free-ride). Furthermore, you know that your attendance at the demonstration will not be critical to its success (fear of inefficacy); in fact it is quite likely that your attendance will go unnoticed.

So what do you do? You could stay home and spend your time doing something else, content in knowing the demonstration is unaffected. But if everyone makes that same decision then the demonstration will be very weak and ineffective. The dilemma of how people can be mobilized to overcome their temptation to stay home and free-ride is an example of the collective action problem.

The collective action problem is found in a wide variety of contexts besides social movements, for example:

\footnotetext{
${ }^{1}$ Though collective action is most frequently studied as the production of public goods, it also encompasses situations that are "social traps" (Komorita and Parks 1994). Social traps are situations like common resource pools (Ostrom 1990) and the "tragedy of the commons" (Hardin 1982), where all individuals are materially tempted to withdraw from a common good, but by so doing they risk its depletion or extinction.
} 
- Charities and Non-profits: You might be tempted not to give to the charities you think are important, or to non-profit organizations like public television. But if no one contributes to them, then these organizations will fail to provide services to needy people and causes that you value.

- Strikes: You might be tempted not to go on strike, but if no one does then you will not have a strong union and the workforce's wages, benefits, and contract enforcement will likely suffer.

- Elections: You might be tempted not to vote for your preferred candidate, knowing that the candidate's success will be unaffected by the absence of your vote. But if none of the candidate's supporters turn out, then the campaign will surely fail.

- Pollution: Individuals may be tempted to litter, not recycle, or, in businesses, pollute to the extent that is materially rational. But if all do so then the environment we share is worse off.

- Giving Blood: Few enjoy giving blood, but if no one were to give blood then the group would be worse off because there would not be enough available for medical emergencies.

- International Agreements: Individual countries are tempted not to sign environmental and non-proliferation treaties, but if no countries do then the world risks cataclysmic consequences.

The collective action problem is interesting in part for its ubiquity. Individuals face collective action problems every day in their efforts to maintain productive collaborations, keep house, and pay taxes. We are further confronted with collective action problems in less mundane, more political and ethical arenas, such as our decisions to join a social movement, vote, or refrain from crime.

The collective action problem also receives attention for its relationship to the most fundamental questions about society. The collective action problem implicitly asks the most basic sociological question, "Why society?" Why do individuals come together in groups to pursue goals with others, rather than behave individualistically, pursuing purely egoistic goals and benefit? Why are there groups, societies, and cultures, rather than just a population of disconnected individuals?

This question was fundamental to western political philosophers of the Enlightenment like Hobbes, Rousseau, and Locke who sought an intellectual basis for understanding government and civil society. Hobbes famously described the condition of man in the absence of civil society as "solitary, poor, nasty, brutish, and short" (1972[1651]). The answer to the collective action problem, thus, promises a way out of this gloomy existence, and a way to understand how it is that society happens.

Western philosophy's answer to the question of how humans emerged from the state of nature to form societies and governments was the "social contract," a set of sacrifices citizens implicitly acquiesce to in return for certain rights and protection from one another; e.g., I agree not to steal in exchange for the privilege to not be stolen from. But this resolution is only satisfactory for political philosophers, as individuals do not actually sign any such social contract. Instead, social scientists, observing that humans from all backgrounds and throughout history have resolved a 
variety of collective action problems, have pursued a wholly different kind of answer to the fundamental question of social order. They have tried to identify aspects of human nature, social structure, and cultural institutions that may help explain how individuals achieve collective action.

In this paper I present a theory of collective action that emphasizes the role of status in motivating group members to overcome the temptation to free-ride and contribute to efforts. I reason that contributions to collective action earn an individual improved status standing and that this status standing in turns motivates further giving to the group. In the sections that follow I present some background to the theory, including past solutions to the dilemma of collective action as well as a review of some relevant research on status processes. I then present the theory itself followed by discussions of various theoretical dilemmas that confront the theory and how they may be resolved. I then trace various theoretical implications and discuss how the theory relates to other models of reputation and prosocial behavior. Finally, I conclude the paper by identifying some areas for future research including possible practical implications of the theory that could be studied in applied settings.

\section{Past Solutions to the Collective Action Problem}

Possibly because of its fundamental nature, the collective action problem is a problem with many solutions, reflecting different methodologies, theoretical approaches, and levels of analysis. Many solutions to the collective action problem offered by sociologists and social psychologists are either tested and evaluated experimentally (Yamagishi 1995), or explored analytically using mathematical and computational models (Oliver 1993). Below I review some examples of solutions to the collective action problem using these and other tools, but this represents only a partial list from one part of the larger collective action literature.

Perhaps the best-known solution offered to the collective action problem is the administration of selective incentives. Selective incentives encouraging contributions to collective action and/or discouraging free-riding were first proposed as a solution to the collective action problem in Mancur Olson's seminal The Logic of Collective Action (1965). Selective incentives are essentially side payments (or punishments) to encourage contribution to public goods. Examples include paying blood donors, "I Voted" stickers given out to voters, tote bags and bumper stickers given to public television donors, prosecuting nonpayment of taxes and theft, and enforcement mechanisms built in to international treaties.

Here I present a novel approach to the solution of the collective action problem based on social status as a selective incentive. The status theory of collective action (hereafter STOCA) I present here asserts that status serves as a selective incentive motivating contributions to the group, and that group members receive status to the extent that they demonstrate group motivation through their contribution behavior. Below I briefly review relevant sociological theory and empirical research on status. I then formally present the central claims of the theory.

\section{Relevant Status Research}


The proposed theory draws heavily on research from status characteristics theory (hereafter SCT) (Berger et al. 1966; 1972; 1977; 1989). Consistent with SCT, I define status as an individual's relative standing in a group based on prestige, honor, and deference (Berger et al. 1972). SCT describes how individuals in groups become differentiated based on status, making accurate predictions for the levels of influence resulting from differently configured status hierarchies (e.g. Berger et al. 1992). Various salient characteristics such as race, gender, and specific skills combine to produce one's status standing relative to others in a given group. Because definitions of what is status-relevant information are shared within a given culture (Ridgeway and Walker 1995), group members' conceptions of the group's status hierarchy tend to be consistent. Status is conceptualized as relative and zero-sum. Individuals with higher status in a group tend to wield more influence (Berger et al. 1972; 1977), receive more action opportunities (Cohen 1994), are more favorably evaluated (Foschi 1992), and are allocated more resources (Berger et al. 1985).

SCT research has shown that group members voluntarily (and perhaps nonconsciously) reorder status hierarchies based on new salient, status-relevant information (e.g. Fisek et al. 1991; Troyer and Younts 1997). In research on status interventions, designed to raise the status standing of members of disadvantaged groups, individuals process new, status-relevant information when it is provided (e.g. Markovsky et al. 1984; Cohen 1994; but see also Foschi 1992; 1996). The notion that individuals reorder status hierarchies when provided with new, status-relevant information is an important element of the present theory. Traditionally, theories of collective action invoking selective incentives have had to answer the second-order free-rider problem of "who will contribute to the administration of selective incentives?" However, if status information is automatically processed as part of normal impression formation processes, then a second-order free-rider problem need not develop. This issue is addressed in more detail below.

Some past research in the SCT tradition supports the status theory of collective action, in particular my central argument that contributions to public goods improve status standing. Ridgeway $(1978 ; 1982)$ showed in a series of experiments on task groups that low status individuals, such as women in a predominantly male group, advance in status through high-quality suggestions on group tasks. However, this relationship between high performance and status attainment was mediated by the degree of group motivation displayed by the women. Women who presented themselves as highly group-motivated achieved increased status as a result of their high performance, while high-performers who did not make efforts to appear groupmotivated did not improve their status. This research suggests a relationship between the degree to which a group member is perceived by others to be group motivated and her status standing. Related anthropological field research has also shown how contributions to public goods such as food (Lemonnier 1996) and military service (Chagnon 1988; Patton 1996) can determine social status.

Research on the relationship between power and status suggests further support for the notion that appearing group motivated can help individuals gain status in groups. Willer et al. (2005) found that more powerful individuals gain status in the eyes of observers of their power use, but only when they avoided being perceived as 
selfish. In this experiment, only powerful actors who did not appear to capitalize on a structural advantage gained status through power use. Power users in networks that held obvious structural advantages were seen as more selfish and gained less status. Similarly, Willer et al. (2002) conducted two experimental studies showing that actors in high power positions who made philanthropic contributions to a common pool benefiting the participant improved their status standing in the eyes of the participants. However, power users who refused contribution did not gain any more status than that accorded to low power actors. This research indicates that apparent group motivation is an important mediator of the relationship between power and status, and may itself exert a main effect on status standing.

The status theory of collective action departs from status characteristics theory in emphasizing status-seeking behavior. Consistent with research in the status attainment literature (e.g. Sewell et al. 1969; 1970), the theory assumes that individuals wish to improve their status standing in groups. While much research in status characteristics theory has addressed what factors determine an individual's status standing, that individuals are motivated to gain status is not an assumption of the theory. However, the status attainment literature assumes status is akin to a scarce good that individuals pursue as they would any valued resource. In these literatures, status is valuable not only for its possible material ends, but also simply because people value what others think of them.

The STOCA also differs from SCT in its scope. The STOCA is intended to apply in collective action situations where a group of individuals shares an interest in producing a public good, but are also motivated to free-ride. The scope of SCT is limited to task groups whose group members are both collectively- and task-oriented (Berger et. al. 1972, 1977). These scopes are related in their emphasis on groups of individuals pursuing shared goals; this suggests that the status dynamics of SCT are likely to apply in the scope of the STOCA. However, these scopes also depart in a significant way. In collective action and exchange situations group members have mixed motives because elements of the settings simultaneously promote collectivism and individualism (Thye 2003). Individuals in collective action situations are tempted to free-ride, and many often do. However, SCT applies only in settings where all individuals are motivated to help the group. Although the distinction is subtle, precise statements of scope conditions are important for establishing exactly where a theory is predicted to apply, where theories overlap, and when they compete (Walker and Cohen 1985).

\section{A STATUS THEORY OF COLLECTIVE ACTION}

Based in part on the above arguments, I detail the following theory of collective action and status (Willer 2009). Table 1 gives definitions of key terms, a statement of scope, and the propositions from the theory. The scope of the theory encompasses collective action situations as conventionally defined, where groups desire the production of a public good that would benefit all members, but face a dilemma in that the good's production requires costly contribution from the group's members. Critical to the theory is the concept of "group motivation" (Ridgeway 1982), defined here as the extent to which the individual values the group's interests relative to the individual's 
own. I further assume, consistent with much past research (Ball and Eckel 1996, 1998, Ball et al. 2001, Huberman et al. 2004) that individuals value improved status standing.

[Table 1 about here]

The theory is relatively simple. I argue that group members assess an individual's apparent group motivation as a function of how much the individual's contributions to group efforts were costly to the individual and benefited the group. Thus contributions that are of negligible cost, or are even directly beneficial, to an individual will not suggest group motivation to others. Likewise, contributions that do not in fact help the group, even if they involve self-sacrifice, will also not cue perceptions of high group motivation. Though benefit to the group is a function of absolute resources contributed, I argue that perceived cost to the individual is a function of the proportion of available resources contributed. I.e. perceptions of the cost to the individual are not absolute, they are relative to how much she or he could give. In this way, both the absolute amount contributed, and the amount contributed relative to available resources, lead to greater perceived group motivation.

I argue then that individuals will earn improved status standing in the eyes of other group members to the extent that they are perceived as group motivated. In turn, as a consequence of this improved status, individuals will be cooperated with more, receive gifts of greater value, and wield more influence over group members. Further, because people value improved status, the receipt of expressions of greater respect from group members will lead the individual to view the group more positively including feelings of group solidarity and identification - and possess greater actual group motivation. As a consequence of this greater group motivation, individuals who have received status rewards for past contribution should contribute at higher levels in the future.

Figure 1 portrays the theory as a path diagram wherein all arrows indicate positive relationships (Willer 2009). Note in particular the "virtuous cycle" linking contributions to group efforts, perceived group motivation, enhanced status, expressions of improved status, enhanced group motivation, and greater future giving. One implication is that low contributors will receive low status and will give less in the future, as high contributors earn improved status and give more subsequently. It is important to note here that the long-run consequences of the virtuous cycle require empirical investigation.

[Figure 1 about here]

Another caveat that it is important to note is that status is conceptualized here, consistent with SCT, as relative and zero-sum. Thus, it is not the case that all can be high status in a group, even if all have contributed a great deal to group efforts. Groups that mobilize very high levels of average contributions to group goals are expected to have distributions of status standing roughly like groups with very low levels of contribution. Below I discuss some possible advantages of this aspect of status as an incentive for contribution.

It is also worth noting that theory argues for a fundamentally different process than a direct exchange of approval for resources between an individual and the group. Rather, I argue that individuals' earn improved status in groups following collective 
action contribution because group motivation is perceived as a meritorious trait closely tied to status (Ridgeway 1982). Further, the effect of improved status on subsequent contributions to group efforts is also not theorized in terms of exchange. Rather, I argue that greater respect leads individuals to actually value the group more, leading in turn to greater contributions.

Willer (2009) offered several experimental tests of predictions derived from these propositions. That research found that high contributors to collective action earn an individual improved status relative to low contributors. Furthermore, these status gains were mediated by perceptions of high contributors as group motivated. High contributors also tended to be cooperated with more, earn gifts of greater value, and wield greater influence over other group members, again as compared with low contributors. Finally, when contributors received information indicating that they were highly respected by other group members, they tended to view the group as having greater solidarity, identify with it more, and make greater contributions in subsequent collective action. This increase in contribution for individuals who earned higher status was mediated by an increase in self-reported motivations to help the group. This initial research offers strong support for the claims of the theory.

\section{FURTHER DEVELOPMENT OF THE THEORY Valuing Status}

The notion that status may serve as an incentive for contributions to collective action did not escape Mancur Olson, who noted that "people are sometimes also motivated by a desire to win prestige, respect, friendship, and other social and psychological objectives" (1965, p.60). That status is a valued resource to individuals is widely assumed in anthropology and sociology, though it is difficult to show directly. As cited above, research in the status attainment tradition shows that models of the individual as a status-seeker offer explanatory leverage in predicting educational and occupational outcomes. Research also shows that in experimental settings participants will forgo profits to gain status (Ball and Eckel 1996, 1998, Ball et al. 2001, Huberman et al. 2004). Unlike material resources that offer declining utility per unit as individuals accumulate them (Friedman 1990), no evidence exists that that individuals' desire for status decreases as standing improves. In this way, the informal incentive of status may be more effective in the long-term than formal incentives, each increment of which may be less valued than the last.

While past theory and research demonstrates that people are concerned about others' opinions of them, it is also the case that not all status rewards are likely to be equally valued by the individual. Characteristics of the "audience" observing an individual's contributions to group efforts will likely have substantial effects on the individual's valuation of status rewards received from the audience. This is a possibly fruitful avenue for future research. I predict that the following factors will increase the value placed on status rewards:

- The number of audience members

- The amount of expected future interaction with audience members; i.e., the "shadow of the future" (Axelrod 1984)

- The existence and strength of an identity connection with the audience 
- The relative status standing of audience members

- The individual's liking for the audience

- The amount of agreement among audience members on relative status standing

- The emphasis placed by audience members on group motivation relative to other status-relevant characteristics

- The apparent willingness of audience members to revise their conception of the status hierarchy

\section{Earning Status Through Contribution}

As noted above, perceptions of group motivation are determined by perceptions of how self-sacrificial and group beneficial an individual's contributions to group efforts are perceived as being. Some factors which may increase the actual or apparent group benefit of a given contribution include:

- The size of the contribution relative to that of other group members

- The value placed on the public good by group members

- The criticality of the contribution (to what extent is the contribution seen as essential to group benefit)

Additionally, factors which increase the actual or apparent self-sacrifice of a given contribution will also serve to increase the individual's apparent group motivation. These factors include:

- The proportion of available resources contributed

- The smaller the size of the audience believed to know about the contribution (smaller is more impressive and anonymous giving is most impressive

- The apparent sincerity of the giving

- Knowledge that the giver was uncertain that his or her contribution would in fact matter

Some of these factors have been examined in past research. For example, I found that contributions of greater proportions of available resources earned a contributor greater status in the eyes of other group members, and this effect was mediated by the contributor's apparent group motivation (Willer 2009: Study 3). Additionally, evidence

exists that observers are more impressed by contributions that were ostensibly made anonymously than those that were made (Barclay and Willer 2007).

Issues of Scope

While as originally formulated the theory applies only to collective action settings, there is good reason to think that this scope could be expanded in future research. In particular, it is very likely that contributions to collective action that do not directly benefit individuals who are aware of the contributions will still earn the contributor status in the eyes of that observer. For example, contributions to Hurricane Katrina relief are likely viewed as meritorious and earn respect from those who were affected by the hurricane and those who were not. Consistent with this, I found that contributions that were observed by someone not involved in a collective action were rewarded with status in the same way as they were by fellow group members (Willer 
2009: Study 2). This study's finding underscored that generous behavior can earn a high contributor diverse social and material benefits even outside the group from those who have reliable information on that contribution behavior.

While it is intuitive that one need not directly benefit from generous behavior in order to respect it, this fact poses theoretical challenges. Status is typically defined as relative standing in a group hierarchy. For the theory to be extended to apply to the perceptions of observers not involved in the group this conception of status may need to be revised or extended.

Similarly, it is very likely that the basic dynamics of earning status for generous behavior would apply to unilateral giving behavior (e.g., helping, giftgiving) in a dyadic context as well. For example, Flynn et al. (2006) found that high self-monitors were able to elevate their status by establishing a reputation $\mathrm{s}$ as generous. Additionally, with my colleague Ko Kuwabara, I collected data on the attitudes individuals held of other participants who had performed in either a cooperative or non-cooperative way in several rounds of a "trust game" with them (see Kreps 1990). More trustworthy individuals were rated as much higher status than less trustworthy ones (Willer and Kuwabara 2002).

In such contexts, contributions were not made to a public good, but rather are made to an individual in a dyad. Such contexts challenge the theory's scope limitation to collective action settings and the conceptualization of group motivation as perceived motivation to help the group, rather than specific others. Both the classes of behavior described in this section clearly suggest that extensions of the theory are warranted. The respect that unilateral gift-giving earns the giver and the receipt of respect from observers outside the group benefiting from a collective action contribution, suggest that the processes identified here may be general to the perception of prosocial behavior - behavior which benefits others, often at a cost the self - in general.

\section{THEORETICAL IMPLICATIONS}

\section{The Paradox of Reward-Driven Generosity}

The theory predicts that individuals who contribute to collective action earn improved status, as well as other social and material benefits, because their contributions indicate their group motivation. How does the status awarded to high contributors to collective action affect their subsequent contributions? The simple and conventional answer to this question would be that the expectation of status and other social and material rewards would be weighed by group members as counteracting material disincentives for contribution in collective action settings, making it no longer against an individual's self-interest to contribute. In this view status operates as a selective incentive for contributions from forward-looking, rational group members.

This interpretation is logical and may explain much observed phenomena. However, there is also much reason to question the assertion that status is explicitly, consciously weighed as a potential payoff for contribution in cost-benefit calculations conducted by each group member, as traditional rational choice theories would assert. The conclusion that status rewards affect individuals' forward-looking cost-benefit 
analyses is an incomplete explanation of the role status rewards may play in encouraging collective action contributions.

In particular, the traditional forward-looking account fails to explain how it is possible for individuals to respond to status rewards while also being, or at least seeming, sincerely generous. The forward-looking model suggests that generous individuals are in actuality wholly selfish, giving to others purely in an effort to pursue personal gain through strategic reputation building. But this view cannot be easily reconciled with the evidence for sincere generosity.

There exists real evidence from everyday experience for the existence of sincere generosity and concern for others. People report feeling real concern for others' welfare. People give to charities anonymously. People tip in restaurants in foreign cities they will never return to (Frank 2004). People are often pleased to see that the recipient of a gift has enjoyed the present. People do research on charities to assure themselves that their contribution will maximally benefit others. Finally, experimental research further shows that altruism (Roth 1995), norm enforcement (Fehr and Gachter 2002), cooperation (Ledyard 1995), and other apparently selfless behaviors can persist even when all apparent reputational incentives are eliminated. The most justified and parsimonious conclusion is that generosity (i.e., group motivation) is real, and not simply an illusion created by conscious, forward-looking, selfish pursuit of reputation gain.

But even though individuals are generous, they also respond to status incentives in apparently selfish ways, suggesting a "paradox of reward-driven selfish generosity." People tend to give more in public than in private (Andreoni and Petrie 2004). Likewise, they are less likely to perform selfish behaviors like littering or not tipping when others are watching and reputation is on the line. Individuals are more likely to grant a requested favor when asked in front of a third party. Charities successfully encourage contributions by conspicuously advertising significant donations. University donors give greater gifts in order to have their names affixed prominently to buildings or professorships.

In addressing the paradox of how individuals could appear generous and experience feelings of generosity, while also seeming to respond to incentives encouraging that generosity, Frank proposed an evolutionary account (1987; 1988). In this account Frank recognized that we encounter substantial rewards for behaving in a prosocial manner, such as finding suitable mates and gaining opportunities for profitable cooperation with others. Receipt of these rewards contributes to an individual's reproductive fitness. Thus, individuals with a genetic predisposition to interact generously and honestly with others may survive and reproduce at higher rates, thereby disproportionately passing on a genetic basis for cooperation and prosociality to future generations.

\section{Learning to Contribute}

In the STOCA I propose another mechanism for resolving the paradox between sincere generosity and individuals' responsiveness to incentives encouraging prosociality, the paradox of selfish generosity. I argue that we learn to be generous. I argue that status rewards encourage generous behavior not through the prospect of 
future rewards, but through social reinforcement of past generous behavior. I argue that individuals will be more likely to give to the group again after past contributions have been positively rewarded with status rewards.

Thus, individuals may first give to their group because of their sincere concern for the group members, strong identification with them, conviction to the cause, or some combination of these and other motives. Whatever that basis of initial giving may be, once they receive status rewards for contributing, the individual's group motivation and propensity for future contribution are reinforced. Status rewards for contribution in this way can encourage individuals' future motivation to help the group without being explicitly weighed as a reward to be pursued in the future.

This account and Frank's are more theoretically satisfactory than alternate models where individuals only feign concern for others. Both the learning and evolutionary accounts can be resolved with the evidence for sincere generosity, and therefore offer a way out of the apparent paradox of selfish generosity. Both my and Frank's accounts do not require a conscious awareness of the role incentives play in encouraging our generosity, an awareness that could threaten to undermine the sincerity of that generosity. In Frank's theory, we are not aware of the role incentives play in encouraging us to be generous because the effect has occurred across generations not within, through the process of natural selection. In my theory, we are not aware of the effects of these incentives because they operate through a nonconscious learning process.

I also assert that status rewards for contribution encourage positive feelings towards the group and its members. In contrast to groups whose members offer an individual no recognition for costly contributions to group goals, those which respond by respecting contributors at greater levels will promote positive associations with the group among those they reward. In this way the theory also helps to explain the evolution of feelings of solidarity and group identification. An empirical test offered support for these claims, showing that contributors who received evidence of improved status standing reported greater group motivation, grater feelings of solidarity, identified more with the group, and contributed more to the group subsequently (Willer 2009: Study 4).

\section{THEORETICAL DILEMMAS IN THE CONFERRAL OF STATUS \\ The Second-Order Free-Rider Problem}

The theory presented here is based on selective incentives. Selective incentives encouraging contributions to collective action and/or discouraging free-riding were first proposed as a solution to the collective action problem in Mancur Olson's seminal The Logic of Collective Action (1965). The administration of a selective incentives system, however, may create a new collective action problem, known as the "secondorder free-rider problem" (Oliver 1980; Heckathorn 1989). While all individuals presumably desire selective incentives to motivate the production of public goods, all are tempted to free-ride on the sanctioning efforts of others. Put simply, who will contribute to the administration of selective incentives? Because a selective incentive system benefits the group but is costly to individual group members, then it is itself a public good and poses its own collective action problems. A group could invoke 
selective incentives to compel group members to pay for selective incentives, but that would create a third-order free-rider problem, and so on. ${ }^{2}$

One might assume that in invoking status as a selective incentive, a secondorder free-rider problem necessarily follows. However, status operates differently than material selective incentives. Much research indicates that group members readily accept new status-relevant information and adjust their conceptions of the group's status hierarchy accordingly (e.g., Berger et al. 1977; Markovsky et al. 1984; Wagner et al. 1986; Berger et al. 1992; Cohen 1994; but see also Foschi 1992; 1996). This research shows that individuals readily update their conceptions of one another in light of new information. Unlike formal incentives, group members do not consider a cost for updating their conception of the status hierarchy in light of new information. Instead they do so automatically.

Thus, for example, when Ann is informed that Bob has behaved in a generous way in the past, she will be more likely to consider Bob more generous and higher status than before. Ann does not consider refusing to give Bob the selective incentive, because the selective incentive Bob seeks in contributing is Ann's (and other group members') perception of him. Though theory and empirical research indicate that individuals readily accept status-relevant information and incorporate it into their conception of the group's status hierarchy, this begs related theoretical questions I address next.

\section{Why Do People Grant Status?}

At first glance, one might suspect that a fundamental contradiction exists in the theory. On the one hand the theory predicts that individuals desire status and seek it by contributing to collective action, but also that they allot status to others for their contributions. But if individuals compete with each other for improved rank in a relative status hierarchy, why would they also allot status to one another? Why doesn't an individual who desires status begin by denying others status gains?

This apparent tension between status-seeking and status-granting behaviors is not unique to the present theory. In fact this apparent contradiction can be found between what are perhaps sociology's two leading bodies of research of status processes: the status attainment research tradition (e.g. Sewell et al. 1969; 1970) and status characteristics theory (Berger et al. 1972; 1977). Status attainment research features the plausible central assumption that individuals seek to improve their status. SCT, on the other hand, focuses on how status hierarchies are organized and, in turn, shape behavior. SCT argues, and research has shown, that individuals attribute status in light of new status-relevant information. Between these two core assumptions arises the previously cited tension: if individuals seek higher status (as in status attainment research) why would they freely attribute improved status to others in light of new status-relevant information (as in SCT)?

One reason people compete for status, but remain willing to attribute improved rank to others, is that individuals may suffer a status loss if they withhold status from

\footnotetext{
${ }^{2}$ Despite theorists' focus on the second-order free-rider problem, individuals readily overcome the dilemma in practice by punishing free-riders even when punishment is costly (Yamagishi 1986) and can not materially benefit the punisher in the future (Fehr and Gachter 2002).
} 
others. There exists a social stigma for being "sour grapes" and failing to "give credit where credit is due." This stigma arises in part because denying others credit is transparently selfish and, as I argue, selfishness hurts an individual's status standing. Research on the Shuar in South America showed that the degree of respect shown for altruists was positively correlated with an individual's status (Price 2003). This research suggests a relationship between giving due credit and one's own status standing. In addition, more recent research has shown that individuals lose favor among group members when they are viewed as maintaining overly positive views of their own status (Anderson et al. 2006). Though the exact reasons remain open for future study, empirical data suggests that people do solve the sour grapes problem in practice, readily incorporating status-relevant information into their conceptions of the status hierarchy.

\section{The Problem of Information Sharing}

Another theoretical complexity that I address in this section concerns information sharing. In order for a selective incentive system based on status to be sustainable in a group it is essential that group members share information. Individuals' behavior in social dilemmas is not always visible to all group members. Thus, in order for an accurate, legitimate, and broadly perceived reputation system to be maintained in relatively large populations, group members must engage in efficient and thorough information exchange on one another's past behavior.

But a dilemma exists. Information on group members' past prosocial behavior is a potentially valuable resource because it allows the owner of said information to know who in the group to interact with in future endeavors. At the extreme, monopolizing this valued information offers privileged access to resources by guaranteeing the individual profitable cooperation experiences with the most prosocial group members. Thus individuals may be tempted to hoard their own information on others' past behavior. But if information on group members' past generosity is hoarded then the reputational incentives for contribution are reduced because the quality of information available to group members is weakened. ${ }^{3}$

Despite this apparent dilemma, in practice we see that individuals appear to resolve the problem effortlessly. Not only do people freely gossip about others, but they seem to do so with special relish in status-relevant domains such as others' relative selfishness or generosity. There are several theoretically plausible reasons why individuals might engage in free information sharing regarding other group members' past contribution behavior.

One solution to the dilemma is for individuals to reciprocally exchange valued information. While it is clearly the case that people regularly trade information on one another, we also observe unilateral volunteering of information in everyday interaction. It may be that these are the initiations of reciprocal exchanges, carrying an implicit expectation that information will be returned in the future. However, it seems likely that valuable information on reputations is sometimes transmitted without expectation of reciprocity.

\footnotetext{
${ }^{3}$ Other theorists have modeled gossip at the group level (Wilson et al. 2000), an approach that avoids this dilemma, but begs new theoretical entanglements associated with group-level selection.
} 
Another reason why individuals might volunteer valuable information on group members' past levels of generosity is to advertise the extensiveness of their social networks. By passing on information that only they know, individuals can demonstrate their access to privileged information, popularity, and influence over the group's information. Given individuals' desire for prestige, this is an intuitive reason to pass on valuable information.

Finally, perhaps the most compelling reason why individuals would gossip about group members' past behavior in collective actions is to deter future exploitation. By passing on one's information on others' reputations, an individual signals that she would be costly to defect on. A smart, selfish person would be attuned to this and be less likely to behave selfishly towards someone with extensive social networks and the willingness to use them to communicate information about prosocial and antisocial behavior.

\section{ALTERNATIVE MODELS OF REPUTATION AND PROSOCIALITY}

A variety of research from evolutionary biology and experimental economics is relevant to the present theory, in some cases either supporting or competing with it. Recent research on indirect reciprocity has advanced the notion that prosocial behaviors are rewarded with, and perhaps motivated by, reputational benefits. ${ }^{4}$ Whereas reciprocity describes the tendency of individuals to directly return favors to others who have helped them in the past, indirect reciprocity occurs when an individual is rewarded for being generous to someone else in the past. Indirect reciprocity has been demonstrated empirically (Wedekind and Milinski 2000; Milinski et al. 2002; Engelmann and Fischbacher 2003; Barclay 2004) and shown to be evolutionary stable (Nowak and Sigmund 1998). Reputation is critical to indirect reciprocity, with an individual's reputation for past prosocial behavior leading to future material benefit.

A variety of accounts exist for indirect reciprocity effects. Theories of image scoring (e.g. Nowak and Sigmund 1998) argue that individuals keep counts of the rates of cooperation of others in the population, cooperating conditionally with others who are themselves more cooperative. A competing theory of reputational dynamics based on standing strategies asserts that people are more discerning than this, discriminating between whether others in the past cooperated with known cooperators or defectors, choosing to indirectly reciprocate only cooperation with other cooperators (Leimar and Hammerstein 2001). Although standing strategies have superior evolutionary stability (Leimar and Hammerstein 2001; Panchanathan and Boyd 2003), some empirical research better supports image scoring perhaps because of its more limited cognitive processing demands (Milinski et al. 2001).

Past research has demonstrated that indirect reciprocity exists, but has not yet explained it. Research on image scoring extends research on indirect reciprocity, investigating when an individual may benefit from prosociality through reputation building. Theories of costly signaling attempt to account for a different, perhaps more

\footnotetext{
${ }^{4}$ I refer here to theories of "reputation" rather than "status" since status is here conceptualized as a social reward, while some theories in this literature model reputation as valued by actors purely as a strategic means to material ends.
} 
fundamental question: Why do individuals indirectly reciprocate? What do people see in prosociality that prompts them to offer material rewards to "good citizens?"

Costly signaling theories assert that individuals behave prosocially in an effort to signal some underlying desirable trait (Frank 1988; Zahavi and Zahavi 1997; Roberts 1998; Smith and Bird 2000; Gintis et al. 2001). In a classic example, the peacock's magnificent tail is theorized to serve as a signal of underlying genetic fitness. This signal is honest by virtue of its costliness. The peacock's tail signals underlying fitness reliably because it requires from an individual a substantial surplus of resources to afford it in the first place (Zahavi and Zahavi 1997). Costly signals are only effective to the extent that they have "broadcast efficiency" making them broadly perceived (Smith and Bird 2005). Through frequently invoked, costly signaling accounts as yet offer no solution to the question of what is being signaled through prosociality among humans.

Costly signaling theories argue that prosocial behavior earns an individual important reputational benefits because it reliably indicates underlying desirable trait(s) of the signaler. In contrast to the present theory, past research and theory emphasizes the signaling of traits traditionally recognized as related to evolutionary fitness, such as strength or skill (Smith and Bird 2000) or accumulated material wealth (see Veblen 1953 [1899]). Past research has less often emphasized the role of prosocial behavior in signaling an individual's underlying group motivation (Roberts 1998; Barclay and Willer 2007).

The present theory is a costly signaling theory, though not necessarily an evolutionary one. The theory argues that the underlying characteristic signaled by prosocial behavior is group motivation. Costly contributions to group efforts serve as signals of the contributor's motivation to help the group, signals that are reliable precisely because they are expensive to fake. The theory further asserts that group motivation is a valued characteristic that earns the signaler status and a variety of material rewards. In one empirical test, I found that a generosity-signaling rather than a wealth-signaling theory better accounted for reputational benefits for prosocial behavior (Willer 2009: Study 3; see also Hardy and van Vugt 2006).

\section{DIRECTIONS FOR FUTURE RESEARCH}

\section{Group Dynamics of Status and Collective Action}

The theory points to a possible drawback of formal incentive systems intended to encourage contributions to public goods. Contribution in the context of material selective incentives is not easily interpreted as generous or selfish. A citizen who pays her taxes may just as likely do so out of patriotism as fear of retribution from the government. The attributional ambiguities posed by contributions in the presence of formal sanctions undermine the informal, status rewards system by making the assessment of group motivation impossible. Indeed, we pay no extra respect to someone for paying their taxes because it does not necessarily indicate concern for the group. These sorts of effects of formal sanctioning systems are suggested by recent research on how formal sanctioning may undermine trust and altruism in group members (Mulder et al. 2006; Fehr and Rockenbach 2003). 
The theory also suggests that the character of a group's status hierarchy may encourage or impede contributions from its members. For example, relatively young or informal groups without established status hierarchies may thrive as individuals compete for prestige in the group by demonstrating their concern for the group. Conversely, formal organizations and other groups with legitimate or rigid status hierarchies may struggle to promote maximal contributions from their members unless they can successfully provide some alternative mechanism for intra-group status mobility. Most formal organizations do resolve this problem with the promise of promotion for productivity. Groups with highly unequal status hierarchies may also face impediments to group productivity, inasmuch as group members may give up in the pursuit of improved rank when the gaps between status positions are too large.

Another implication of the theory is that, relatively high contributors receive status for their contributions and give more subsequently, while lower contributors receive low status and subsequently give less. Over time, this implies that groups may tend to bifurcate into subgroups of contributors and free-riders. This dynamic would be at least superficially similar to Michels" "Iron Law of Oligarchy" (1962), which describes a tendency for a subgroup of early contributors to assume positions of leadership in the group and take on the majority of decision-making, and deserves further study. In general, however, caution should be used in deriving macro-level implications from the present theory given its focus on the micro-level dynamics of collective action contribution and status (but see Kitts 2006).

At the extreme, if individuals become too low status in the group they may find their position undesirable and (if possible) exit the group. On the flip side, individuals may be shunned from the group for non-contribution to group efforts, or excluded from the benefits of the public good. Whatever the mechanism, when free-riding group members leave the group and its status hierarchy, one effect is to diminish the standing of the remaining group members. This dynamic may actually contribute to group productivity by periodically lowering group members' relative positions in the status hierarchy, thereby encouraging higher levels of contribution from the remaining group members in order to achieve their former status positions. Thus, groups with permeable boundaries may face difficulties in retaining members, but ironically may become more productive in their absence.

There are other ways in which group composition could affect group productivity based on the theory. People should contribute at higher levels in groups composed of individuals whose opinions they value highly. Perhaps the often replicated finding from social identity theory that groups sharing high levels of identification are more productive really reflects the tendency of individuals to contribute in pursuit of status rewards, combined with individuals' greater concern for the standing in the eyes of people with whom they share an identity connection.

\section{Interactional Dynamics of Status and Collective Action}

The micro-level dynamics of the theory also leave open questions deserving further attention. For example, there is conflicting evidence regarding how closely group members analyze the sincerity of contributions to group goals. In a study of a realworld water shortage in a college dormitory, and the attendant collective action 
problems, researchers at Princeton University found that individuals who helped out in the water shortage by reducing their water intake tended to view others who also withheld consumption of water during the shortage as more altruistic than themselves (Monin and Norton 2003; see also Miller et al. 2000). The authors interpret this finding as evidence of the correspondence bias. While the individuals studied realized that their own reduced consumption was in part a product of social pressure, they tended to take the reduced consumption of their peers at face value, attributing it to an altruistic disposition. This finding is echoed by the present theory, where I argue that individuals tend to take others' apparently generous behaviors at face value, attributing group motivation and status to those who sacrifice more for group goals.

However, other research show limitations to the assumption that individuals always take others' behaviors at face value. Fein et al. found that study participants were less likely to make correspondent attributions when led to suspect that a target might be trying to promote him or herself (1990, Study 1; Fein 1996). This research suggests that we are more likely to make accurate attributions when suspicious about the motives of others. But are people readily suspicious of the motives of apparent altruists?

In an unpublished vignette study, I investigated whether a hypothetical person's claims to have various positive, status-worthy, or negative, unworthy traits, would be accepted (Willer 2004). I asked study participants to what extent they would believe and trust a person who claimed to have one of a series of traits, including rudeness, intelligence, dishonesty, unhappiness, selfishness, and generosity. Of the various traits studied, participants were least willing to take claims of generosity at face value in the study. Targets who claimed that they were generous were also seen as the least trustworthy.

There is further evidence that suggests we do not entirely take contributions at face value. For example, though we respect an individual for contributing to a charitable cause, we would be far more impressed if we found out that she had intended the donation to be totally anonymous (Frank 2004; Simpson and Willer 2008). This suggests that we do not back totally correspondent attributions of group motivation for apparently generous behaviors.

Not all theories of reputation argue that individuals attempt to assess the intentions of other contributors (e.g., image scoring). Research has found, however, that the intentions of an interaction partner impact the dynamics of direct reciprocity (Falk et al. 2000). Further, my research finds that the effect of contributions on resulting status standing is mediated by assessments of the contributors underlying group motivation (Willer 2009: Studies 1-3) suggests that individuals are attuned to the intentions of other group members. Though I found that individuals readily attributed higher status to higher contributors, I also found that the underlying disposition of the contributors (specifically, their group motivation) was an important consideration in this process.

The implication of the research is that individuals generally do take apparently reliable information on contribution behavior as evidence of underlying disposition and intentions, and accord status afterwards proportionally. Thus, while we are quite discerning about information regarding others' group motivation, we also take into 
account all available information. Further, assessing intentions and the underlying disposition of contributors is an essential aspect of reputation systems in collective action, in part because intentions are critical to predicting the contributor's likely future behavior.

\section{Practical Implications for Collective Action}

The theory indicates some real world strategies for improving the success of collective action. The main variable that the theory would suggest as useful for organizing real world collective action is the visibility of contributions. There is good reason based on past research and the theory to expect individuals to give more when contributions are public. The present research shows that public contributions lead to status in the eyes of others, and that these status rewards encourage greater subsequent contributions. For example, a classic and effective union-organizing tool is to have regular organizing meetings where individuals present their contributions from the past week, and future contributions are solicited from members. These presentations serve to strengthen the relationship between contribution and status standing by making contributions visible.

One larger scale intervention that could be helpful for mobilizing greater giving to diverse charities would be to set up an on-line database documenting the charitable giving of Americans to a variety of organizations. Charitable organizations would be asked to provide regular lists of all charitable donations (including money donated and hours volunteered), which would then be listed on the webpage. The database would be searchable in the same way as the current "www.fundrace.org," where you can search for the amounts all Americans contributed to various political campaigns. It is possible that people would give more to charities knowing that their contributions could be seen on an easy-to-access public webpage. Further, if the number of registered charities became extensive enough, it could become a sign of selfishness to not appear on the site.

An interesting wrinkle of such an approach is that people might begin to strategically "game" the process, perceiving a self-glorifying stigma for giving to charities that register with such a webpage. To show their greater group motivation, individuals might start to give to unregistered charities more, or give anonymous donations to registered ones. Such behavior would be fascinating, but also hard to manage in practice. One possible response would be to require participating charities to only accept non-anonymous gifts. Also, rhetorically emphasizing that the page's purpose is to "give credit where credit's due" might also help to deter cynicism about public donations. Nonetheless, substantial research is required before such an intervention is advised.

Another useful mobilizing technique could be to strategically compose the immediate audience that observes individuals' contributions in order to enhance the value of resulting status rewards. Having donors or volunteers work next to or meet with like-minded, similar individuals that he or she is likely to interact with again in the future would enhance expected status rewards. Also, frequent social functions and organizing around small group meetings helps individuals develop relationships, and over time value one another's opinion more. 


\section{CONCLUSION}

\section{Sartre's Error Solves Hobbes's Dilemma}

It's worth noting that the status solution to the collective action problem offered here fits the problem very well in a couple ways. The status incentive system is an informal system that does not require any central, formal organization. The status rewards available to contributors are distributed across the minds of other group members. This means that the system is not easily destroyed or undermined, and does not require any explicit management or leadership to be maintained.

Also, status incentives for contribution to collective action increase as the collective action becomes more difficult. As a collective action problem gets harder and harder to tackle, requiring greater sacrifice from group members, status rewards also increase since contribution under such circumstances indicates even greater concern for the group. This shows that the status incentive system is flexible and adaptive, but without any explicit planning or formal organization. And partly because status rewards adapt to the difficulty of the situation, no collective action need be impossible.

What I have called the "Why society?" question has engaged scholars for centuries before and after Hobbes. The answer to this question promises insights on the evolution of government and social institutions, as well as the movements that we might devise to reform or even overthrow them. Hobbes' Leviathan, the collective force we wield in the creation and maintenance of social order, is not an explicit contract. But perhaps there is an implicit social contract embedded in all of our minds. That social contract, our willingness to behave in basically prosocial ways and make sacrifices for the group's welfare, I argue stems most fundamentally from our concern for what others think of us.

Sartre famously observed that "hell is other people," partly because we our reliance on others' considerations of us leaves us essentially dependent on others for our own happiness (1955 [1943]). Because of this persistent concern for others' approval, we are privately tyrannized by others' opinions, even outside their presence, our view of self being reflected through the eyes of the multitude (Cooley 1902). But I suggest here that Sartre got it wrong. I argue instead that the extremity of our concern for others' opinions of our worth is also one of our greatest qualities for the opportunity it grants: the opportunity for society, government, collective behavior, democracy, solidarity, and the production of public goods. Our concern for others' opinions of us turns out to be a magnetic social force, pulling us together and into group endeavors. In this way it could be said that other people are both the heaven and hell of the human social experience.

Returning to the general question of how people come together in groups, this research suggests that status may be part of the glue that keeps us together, working towards collective goals. There are many viable solutions to the basic question of how we are able to overcome our selfish temptations and opt instead to give to the group and its goals. Past research shows that feelings of shared identity and a common cause may help people become active in groups, as do resources, strong conviction to the cause, and the feeling that you can make a difference. But just as with these and other 
factors, I think an essential part of the social order and what drives our pursuit of common goals is our basic concern for what others think of us. This concern, this desire to be thought well of, the desire for respect from like-minded people, may be a fundamental part of the social fabric; a consideration that binds us together, sacrificing in pursuit of a greater good for the groups we inhabit. 

TABLE 1: The Status Theory of Collective Action (Reprinted from Willer 2009)

\section{Definitions:}

Status - An individual's relative standing in a group based on prestige, honor, and deference (Berger, Cohen, and Zelditch 1972).

Group Motivation - How much an individual values the group's interests relative to his or her own.

\section{Scope Conditions:}

The scope of the theory encompasses collective action situations as conventionally defined, i.e., situations where a public good that is (1) non-excludable (i.e., it benefits all group members), and (2) valued by all group members, (3) requires costly contributions from individuals to be produced.

\section{Propositions:}

1. The more highly group members evaluate (a) the cost of an individual's contributions to the group, and (b) the benefits to the group of an individual's contributions, then the more highly members will evaluate the individual's level of "group motivation."

2. The greater an individual's perceived group motivation, the greater the individual's relative status standing.

3. The greater an individual's status standing, the more group members will yield to the influence of the individual, cooperate with him or her, and give him or her gifts of greater value.

4. The greater the status an individual receives for past contributions, the more his or her group motivation will increase and the more the individual will tend to view the group positively-including identifying with the group more and seeing it as having more solidarity and cohesion.

5. The greater an individual's group motivation, the more the individual will contribute to the group. 


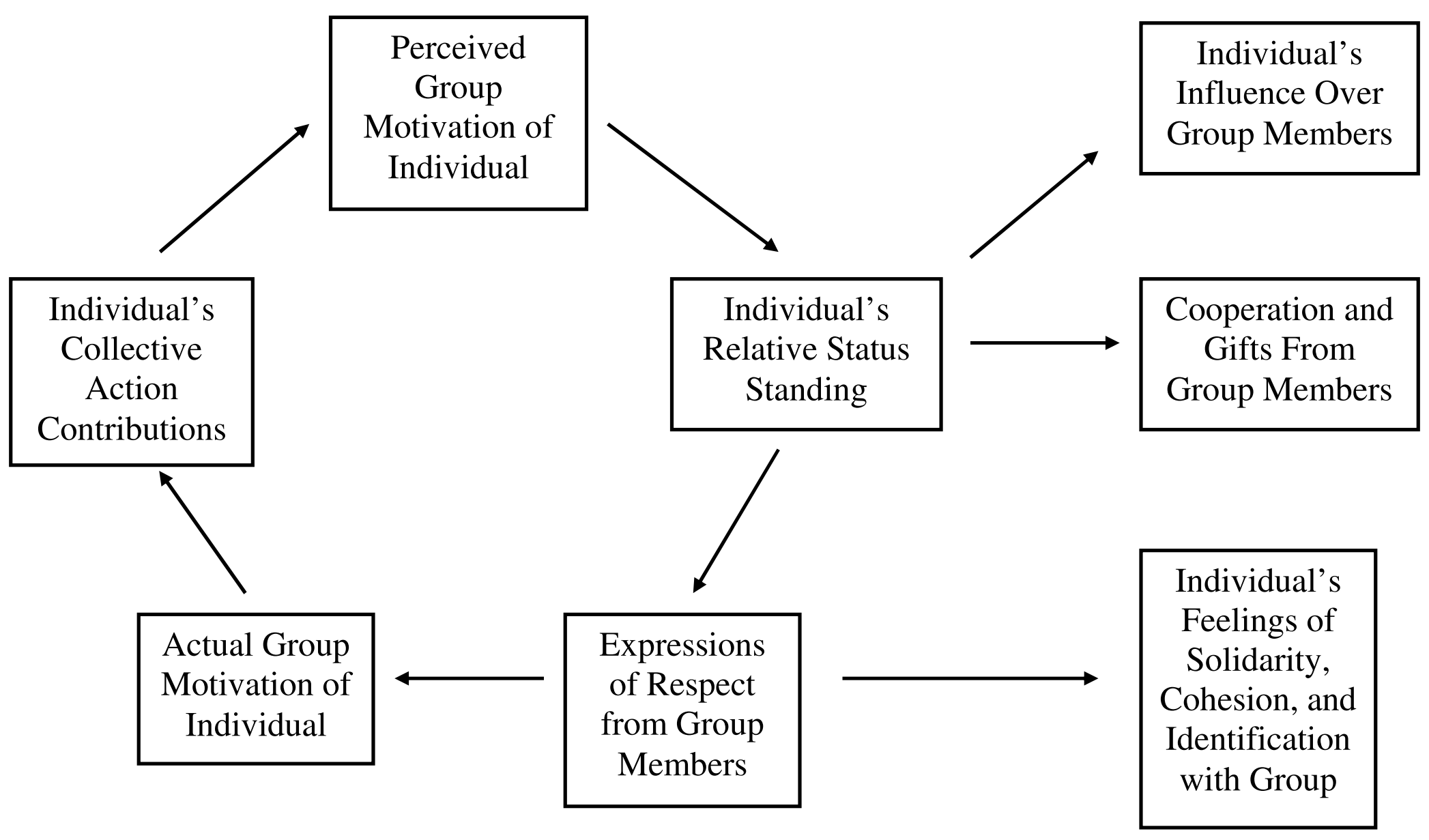

Figure 1. Causal Diagram of a Status Theory of Collective Action (Willer 2009) Note: All arrows indicate positive relationships 


\section{REFERENCES}

Anderson, Cameron, Sanjay Srivastava, Jennifer S. Beer, Sandra E. Spataro, and Jennifer E.Chatman. 2006. "Knowing Your Place: Self-Perceptions of Status in Face-toFace Groups.” Journal of Personality and Social Psychology. 91:1094-1110.

Andreoni, James and Ragan Petrie. 2004. "Public Goods Experiments without Confidentiality: A Glimpse into Fund-Raising." Journal of Public Economics. 88:1605-1623.

Axelrod, Robert. 1984. The Evolution of Cooperation. Basic Books.

Ball, Sheryl, and Catherine Eckel. 1996. "Buying Status." Psychology and Marketing. 13:381-405.

Ball, S., \& Eckel, C. C. 1998. "The Economic Value of Status.” Journal of Socio -Economics, 27, 495-514.

Ball, Sheryl, Catherine Eckel, Phillip J. Grossman, and William Zame. 2001. "Status In Markets." Quarterly Journal of Economics. 116:161-188.

Barclay, Pat. 2004. "Trustworthiness and Competitive Altruism can also solve the 'Tragedy of the Commons." Evolution and Human Behavior. 25: 209-220.

Barclay, Pat and Robb Willer. 2007. "Prtner Choice Creates Competitive Altruism in Humans." Proceedings of the Royal Society of London B: Biological Sciences. 274:749-753.

Berger, Joseph, Bernard P. Cohen, and Morris Zelditch, Jr. 1966. "Status Characteristics and Expectation States.” In Sociological Theories in Progress, Vol. 1. Joseph Berger, Morris Zelditch Jr., and Bo Anderson (Eds.), Pp. 29-46. Boston: Houghton Mifflin.

Berger, Joseph, Bernard P. Cohen, and Morris Zelditch, Jr. 1972. "Status Characteristics and Social Interaction." American Sociological Review. 37:24155.

Berger, Joseph, M.Hamit Fisek, and Robert Z. Norman. 1989. "The Evolution of Status Expectations: A Theoretical Extension." In Sociological Theories in Progress: New Formulations. Joseph Berger, Morris Zelditch Jr., and Bo Anderson (Eds.), Pp. 29-46. Newbury Park, CA: Sage..

Berger, Joseph, M.Hamit Fisek, Robert Z. Norman, and David G. Wagner. 1985. "Formation of Reward Expectations in Status Situations." In Status Rewards and Influence. J. Berger and M. Zelditch, Jr. (Eds.) pp. 215-61. San Francisco: Jossey-Bass.

Berger, Joseph, M.Hamit Fisek, Robert Z. Norman, and Morris Zelditch, Jr. 1977. Status Characteristics and Social Interaction: An Expectations States Approach. New York: Elsevier.

Berger, Joseph, Robert Z Norman, James W Balkwell, and Roy F Smith. 1992. "Status Inconsistency in Task Situations: A Test of Four Status Processing Principles." American Sociological Review. 57:843-855.

Chagnon, Napoleon. 1988. "Life Histories, Blood Revenge, and Warfare in a Tribal Population.” Science 239:985-992.

Cohen, Elizabeth. 1994. Designing Groupwork: Strategies for the Heterogeneous Classroom. New York: Teachers College Press.

Cooley, Charles Horton. 1902. Human Nature and the Social Order. New York: Scribner's. pp. 179-185. 
Engelmann, Dirk and Urs Fischbacher. 2004. "Indirect Reciprocity and Strategic Reputation Building in an Experimental Helping Game.” The Center for Economic Research and Graduate Education, Economic Institute, Prague. CERGE-EI Working Paper Series.

Falk, Armin, Ernst Fehr, and Urs Fischbacher. 2000. "Testing Theories of Fairness: Intentions Matter." Institute for Empirical Research in Economics, University of Zurich. Working Paper \#63.

Fehr, Ernst and Simon Gachter. 2002. "Altruistic punishment in humans." Nature. 415:137-140.

Fehr, Ernst, and Bettlina Rockenbach. 2003. "Detrimental Effects of Sanctions on Human Altruism.” Nature. 422: 137-140.

Fisek, M. Hamit, Joseph P. Berger, and Robert Z. Norman. 1991. "Participation in Heterogeneous and Homogeneous Groups: A Theoretical Integration." American Journal of Sociology. 97:114-42.

Fein, Stephen. 1996. "Effects of suspicion on attributional thinking and the correspondence bias." Journal of Personality and Social Psychology. 70: 11641184.

Fein, Stephen, James L. Hilton, and Dale T. Miller. 1990. "Suspicion of Ulterior Motivation and the Correspondence Bias." Journal of Personality and Social Psychology. 58 (5): 753-764.

Foschi, Martha. 1992. "Gender and Double Standards for Competence." In Gender, Interaction, and Inequality. Cecilia L. Ridgeway (Ed.). New York, NY: SpringerVerlag.

Foschi, Martha. 1996. "Double Standards in the Evaluation of Men and Women." Social Psychology Quarterly. 59:237-254.

Frank, Robert. 1987. "If Homo Economicus Could Choose His Own Utility Function, Would He Want One With a Conscience?" American Economic Review. 77: 593604.

Frank, Robert H. 1988. Passions Within Reason: The Strategic Role of the Emotions. New York: Norton.

Frank, Robert H. 2004. What Price the Moral High Ground?: Ethical Dilemmas in Competitive Environments. Princeton, NJ. Princeton University Press.

Friedman, David. 1990. Price Theory: An Intermediate Text. South-Western Publishing: Cincinnati, $\mathrm{OH}$.

Gintis, Herbert, Eric A. Smith, and S. Bowles. 2001. "Costly Signaling and Cooperation." Journal of Theoretical Biology. 213:103-119.

Hardin, Russell. 1982. Collective Action. Baltimore, MD: Johns Hopkins University Press.

Hardy, Charlie L. and Mark van Vugt. 2006. "Giving for Glory in Social Dilemmas: The Competitive Altruism Hypothesis." Personality and Social Psychology Bulletin. 32:1402-1413.

Heckathorn, Douglas D. 1989. "Collective Action and the Second-Order Free-Rider Problem." Rationality and Society. 1, 78-100.

Hobbes, Thomas. 1972 [1651]. Leviathan. Penguin Books: Baltimore, MD.

Huberman, Bernardo A., Christoph H. Loch, and Ayse Onculer. 2004. "Status as a Valued Resource.” Social Psychology Quarterly. 103-114. 
Kitts, James A. 2006/ "Collective Action, Rival Incentives, and the Emergence of Antisocial Norms." American Sociological Review. 71:235-259.

Komorita, Samuel S. and Craig D. Parks. 1994. Social Dilemmas. Westview Press: Boulder, CO.

Ledyard, John O. 1995. "Public Goods: A Survey of Experimental Research." The Handbook of Experimental Economics. Eds. John H. Kagel and Alvin E. Roth. Princeton, NJ: Princeton University Press.

Leimar, O. and P. Hammerstein. 2001. "Evolution of Cooperation through Indirect Reciprocity." Proceedings of the Royal Society of London B. 268:745-753.

Lemonnier P. 1996. "Food, Competition, and the Status of Food in New Guinea." In Food and the Status Quest: An Interdisciplinary Perspective. eds. P Wiessner and W Schiefenhovel. 219-234. New York: Berghahn.

Macy, Michael W. and Andreas Flache. 2002. "Learning Dynamics in Social Dilemmas." Proceedings of the National Academy of Sciences. 99(3): 7229-7236.

Markovsky, Barry, LeRoy F. Smith, and Joseph Berger. 1984. "Do Status Interventions Persist?” American Sociological Review. 49:373-382.

Michels, Robert. 1915. Political parties: A Sociological study of the Oligarchical Tendencies of Modern Democracy. Glencoe, Il: Free Press.

Milinski, Manfred, D. Semmann, T.C. Bakker, H.J. Krambeck. 2001. "Cooperation through Indirect Reciprocity: Image Scoring or Standing Strategy?" Proceedings of the Royal Society of London B. 268:2495-2501.

Milinksi, Manfred, D. Semmann, and H.J. Krambeck. 2002. "Reputation Helps Solve The 'Tragedy of the Commons.'" Nature. 415:424-6.

Miller, Dale T., Benoit Monin, and Deborah A. Prentice. 2000. "Pluralistic Ignorance And Inconsistency between Private Attitudes and Public Behaviors." In Attitudes, Behavior, and Social Context: The Role of Norms and Group Membership. Eds D.J. Terry and M.A. Hogg. Mahwah, NJ: Erlbaum.

Monin, Benoit, and Michael I. Norton. 2003. "Perceptions of a Fluid Consensus: Uniqueness Bias, False Consensus, False Polarization, and Pluralistic Ignorance in a Water Conservation Crisis." Personality and Social Psychology Bulletin. 29(5): 559-567.

Mulder, L. B., E. Van Dijk, D. De Cremer, and H. A. M. Wilke. 2006. "Undermining Trust and Cooperation: The Paradox of Sanctioning Systems in Social Dilemmas." Journal of Experimental Social Psychology. 42: 147-162.

Nowak, M.A., and Karl Sigmund. 1998. "Evolution of Indirect Reciprocity through Image Scoring." Nature. 393:573-7.

Oliver, Pamela E. 1980. "Rewards and Punishments as Selective Incentives for Collective Action: Theoretical Investigations." American Sociological Review. 85(6):1356-1375.

Oliver, Pamela E. 1993. "Formal Models of Collective Action." Annual Review of Sociology. 19:271-300.

Olson, Mancur. 1965. The Logic of Collective Action: Public Goods and the Theory of Groups. Harvard: Cambridge.

Ostrom, Elinor. 1990. Governing the Commons: The Evolution of Institutions for Collective Action. New York: Cambridge University Press.

Panchanathan, Karthik, and Robert Boyd. 2003. "A Tale of Two Defectors: The 
Importance of Standing for Evolution of Indirect Reciprocity." Journal of Theoretical Biology. 224:115-126.

Patton, John Q. 1996. Thoughtful Warriors: Status, Warriorship, and Alliance in the Ecuadorian Amazon. Dissertation: University of California at Santa Barbara.

Price, Michael E. 2003. "Pro-Community Altruism and Social Status in a Shuar Village." Human Nature: An Interdisciplinary Biosocial Perspective.14(2): 191208.

Ridgeway, Cecilia L. 1978. "Conformity, Group-oriented Motivation, and Status Attainment in Small Groups." Social Psychology. 47, 175-188.

Ridgeway, Cecilia L. 1982. "Status in Groups: The Importance of Motivation." American Sociological Review. 47: 76-88.

Ridgeway, Ceclia L. and Henry A. Walker. 1995. "Status Structures." Sociological Perspectives on Social Psychology. Eds. Karen S. Cook, Gary Alan Fine, and James S. House. Allyn and Bacon: Boston, MA.

Roberts, Gilbert. 1998. "Competitive Altruism: From Reciprocity to the Handicap Principle." Proceedings of the Royal Society of London B. 265:427-431.

Roth, Alvin E. 1995. "Bargaining Experiments." The Handbook of Experimental Economics. Eds. John H. Kagel and Alvin E. Roth. Princeton, NJ: Princeton University Press.

Sartre, Jean-Paul. 1955 [1943]. No Exit and Three Other Plays. Vintage Books: New York.

Sewell, William H., Archibald O. Haller, and Alejandro Portes. 1969. "The Educational and Early Occupational Attainment Process." American Sociological Review. 34: 82-92.

Sewell, William H., Archibald O. Haller, and George W. Ohlendorf. 1970. "The Educational and Early Occupational Status Attainment Process: Replication and Revision.” American Sociological Review. 35: 1014-27.

Simpson, Brent, and Robb Willer. 2008. "Altruism and Indirect Reciprocity: The Interaction of Person and Situation in Prosocial Behavior." Social Psychology Quarterly. 71:37-52

Smith, Eric Alden and Rebecca L. Bliege Bird. 2000. "Turtle Hunting and Tombstone Opening: Public Generosity as Costly Signaling." Evolution and Human Behavior. 21:245-61.

Smith, Eric Alden and Rebecca L. Bliege Bird. 2005. "Costly Signaling and Cooperative Behavior." In The Moral Sentiments: Theory, Evidence, and Policy. Eds. S. Bowles, R. Boyd, E. Fehr, and H. Gintis.Cambridge, MA: M.I.T. Press.

Thye, Shane R. 2003. "Theory Integration and The Status Value Theory of Power in Exchange." Paper presented at the American Sociological Association Meetings. Atlanta, GA.

Troyer, Lisa and C. Wesley Younts. 1997. "Whose Expectations Matter? The Relative Power of First and Second Order Expectations in Determining Social Influence." American Journal of Sociology. 2: 692-732.

Veblen, Thorstein. 1953 [1899]. The Theory of the Leisure Class. New York: Mentor. Wagner, David G., Rebecca S. Ford, and Thomas W. Ford. 1986. "Can Gender Inequalities be Reduced?" American Sociological Review. 51:47-61.

Walker, Henry A. and Bernard P. Cohen. 1985. "Scope Statements: Imperatives for 
Evaluating Theory." American Sociological Review. 50:288-301.

Wedekind, C. and M. Milinski. 2000. "Cooperation through Image Scoring in Humans." Science. 288:850-2.

Willer, Robb. 2004. "Someone Walks up to You...: Attributions and Skepticism on

Status-Relevant Dimensions." Unpublished dataset. Cornell University. Ithaca, NY.

Willer, Robb. 2009. "Groups Reward Individual Sacrifice: The Status Solution to the Collective Action Problem." American Sociological Review. Forthcoming.

Willer, Robb and Ko Kuwabara. 2002. "Status and Trustworthiness." Unpublished datatset. Cornell University: Ithaca, NY.

Willer, Robb, Lisa Troyer, and Michael J. Lovaglia. 2005. "Influence Over Observers of Structural Power: An Experimental Investigation." The Sociological Quarterly. 46:263-77.

Willer, Robb, Reef Youngreen, Lisa Troyer, and Michael Lovaglia. "Power, Status, and Philanthropy." XV World Congress of Sociology. Brisbane, Australia. July 2002

Wilson, David S., C. Wilczynski, A. Wells, and L. Weiser. 2000. "Gossip and Other Aspects of Language as Group-Level Adaptations." In Cognition and Evolution (pp. 347-365 ), Eds. C. Heyes \& L. Huber. Cambridge, MA: M.I.T. Press.

Yamagishi, Toshio. 1986. "The Provision of a Sanctioning System as a Public Good." Journal of Personality and Social Psychology. 51(1):110-116.

Yamagishi, Toshio. 1995. "Social Dilemmas." In Sociological Perspectives on Social Psychology. Eds. Karen S. Cook, Gary Alan Fine, and James S. House.Allyn and Bacon: Boston, MA

Zahavi, Amotz and Avishag Zahavi. 1997. The Handicap Principle: The Missing Piece of Darwin's Puzzle. New York: Oxford University Press. 